\title{
Free access to medicines among older adults in primary care: a cross-sectional study
}

\author{
Isabela Vaz Leite Pinto', Marina Guimarães Lima", Laís Lessa Neiva Pantuzza'", Maria das Graças Braga Ceccato'v, \\ Micheline Rosa Silveirav, Adriano Max Moreira Reis ${ }^{\mathrm{VI}}$
}

School of Pharmacy, Universidade Federal de Minas Gerais (UFMG), Belo Horizonte (MG), Brazil

'MSc. Pharmacist, Municipal Health Department, Municipal Government of Belo Horizonte, Belo Horizonte (MG), Brazil.

(D) orcid.org/0000-0001-6335-5480

"PhD. Associate Professor and Pharmacist, School of Pharmacy, Universidade Federal de Minas Gerais (UFMG), Belo Horizonte (MG), Brazil.

(D) orcid.org/0000-0003-0959-3079

'"MSc. Doctoral Student and Pharmacist, School of Pharmacy, Universidade Federal de Minas Gerais (UFMG), Belo Horizonte (MG), Brazil. (D) orcid.org/0000-0001-9831-8807

"vphD. Associate Professor and Pharmacist, School of Pharmacy, Universidade Federal de Minas Gerais (UFMG), Belo Horizonte (MG), Brazil. (D) orcid.org/0000-0002-4340-0659

vPhD. Associate Professor and Pharmacist, School of Pharmacy, Universidade Federal de Minas Gerais (UFMG), Belo Horizonte (MG), Brazil. (D) orcid.org/0000-0001-7002-4428

viphD. Associate Professor and Pharmacist, School of Pharmacy, Universidade Federal de Minas Gerais (UFMG), Belo Horizonte (MG), Brazil.

(D) orcid.org/0000-0002-0017-7338

KEY WORDS (MeSH terms):

Aged.

Primary health care.

Public health.

Pharmaceutical preparations.

Pharmaceutical services.

\section{AUTHORS' KEY WORDS:}

Elderly.

Medicines.

Access to medicine.

\begin{abstract}
BACKGROUND: Access to medicines is an important indicator of healthcare system quality and capacity to resolve problems. The healthcare system needs to ensure free access to medicines for elderly people, in order to provide greater effectiveness of disease control, thus reducing morbidity and mortality, and improving health and quality of life.

OBJECTIVES: To analyze the frequency of free access to medication among older adults within primary care and determine the factors associated with free access.

DESIGN AND SETTING: Cross-sectional study at two primary care units.

METHODS: Free access was defined as provision of all medicines through pharmacies within the Brazilian National Health System and through the Brazilian program for free medicines in private pharmacies. We investigated the sociodemographic, clinical, functional and pharmacotherapeutic characteristics of older adults. Multivariate logistic regression was performed to identify factors associated with free access to medicines.

RESULTS: This study included 227 older adults, among whom 91 (40.1\%) had free full access to prescription drugs. A direct association with age $\leq 70$ years and indirect associations with polypharmacy and multimorbidity $(P<0.05)$ were found.

CONCLUSIONS: Age $\leq 70$ years increases the likelihood of having free full access to medicines, and older adults with multimorbidity and polypharmacy use have a lower likelihood of access. Identification of factors associated with free access to medicines among elderly people provides elements to guide the Brazilian National Health System in implementing access improvement actions.
\end{abstract}

\section{INTRODUCTION}

The contribution of medicines to better quality of life, recovery of health and increased survival is appreciable. ${ }^{1}$ Thus, resolute public healthcare actions to curb morbidity and mortality are strongly influenced by rational access to and use of drugs. ${ }^{1-4}$

Given the increasing burden of chronic noncommunicable diseases around the world, access to medicines encompassing availability and affordability is a significant public health challenge for both developed and developing countries. The global action plan for noncommunicable disease prevention and control coordinated by the World Health Organization recommends that actions to expand access to medicines should be developed. ${ }^{5,6}$

In Brazil, through the National Drug Policy, measures have been implemented to ensure and expand the population's access to medicines since 1998. In 2004, actions were scaled up when the National Pharmaceutical Services Policy Guidelines were defined. ${ }^{4,7}$ The following stand out among the different strategies for improving access to medicines that are underway in this country: structuring of pharmaceutical services; improvement and innovation of the legal framework for accessing medicines within the Brazilian National Health System; improved organization of financing for public pharmaceutical services; and higher levels of federal resources for procurement of medicines. ${ }^{4}$

Brazil has been experiencing aging of the population as a result of the epidemiological and demographic transition that is taking place in this country. This situation greatly affects the planning of social and healthcare policies, given the increased prevalence of older adults with multiple noncommunicable diseases requiring complex multidrug therapy. ${ }^{1,8,9}$ The National Survey on Drug Access, Use and Promotion of Rational Use in Brazil found that 75.7\% of older adults used 
two or more chronic drugs. ${ }^{1}$ Given this scenario, healthcare systems need to ensure free access to medicines for elderly people, in order to provide greater effectiveness of disease control, thus reducing morbidity and mortality, and improving health and quality of life..$^{3-6}$

Access to medicines is an important indicator of healthcare system quality and capacity to resolve problems and is considered by the United Nations to be an appropriate means for measuring progress towards achievement of healthcare rights. ${ }^{7,10-13}$

Primary healthcare is provided through an extensive network of services and can solve most of a population's health problems. Consequently, ensuring free access to medicines for older adults at this level of care should be a priority. ${ }^{7,9}$

\section{OBJECTIVE}

The aims of this study were to analyze the frequency of free access to medication among elderly people attended at two primary healthcare centers and to determine the factors associated with free access.

\section{METHODS}

\section{Study design and participants}

This was a cross-sectional study conducted at two primary care units (PCUs) located in the city of Belo Horizonte, Brazil. The study population consisted of individuals aged 60 years and over (older adults) who received at least one drug from PCU pharmacies between November 2013 and April 2014. The participants were selected non-randomly, and older adults were invited consecutively to participate in the study in PCU pharmacies. The exclusion criterion was the inability to communicate verbally or visually.

\section{Sample}

The sample size was calculated from data in the computerized pharmacy system of the PCU. The mean monthly number of visits to these pharmacies by elderly people was 483 . Based on the premise that dispensing of chronic care drugs from PCU pharmacies is done monthly, we considered that elderly people who were attended every month were part of the same population. Thus, by assuming that there was a finite population of 483 older adults, with a prevalence value of $50 \%$ for all observed characteristics, and taking a significance level of $5 \%$, confidence interval of $95 \%$ and loss or refusal rate of $10 \%$, the sample size was estimated to be 237 older adults. The "Open Epi" version 3.01 software was used for the sample size calculation. ${ }^{14}$

\section{Data collection and organization}

Data were collected through face-to-face interviews, using a structured questionnaire that was applied by pharmacists and by pharmacy and medical students who had previously received training.
The questions were on sociodemographic, clinical, functional, access-related and medicine-use characteristics. These data were complemented by consulting the medical records. The information on access to medicines covered the period of the last 30 days. The database was created using the Epi Info version 3.5.4 software (Centers for Disease Control and Prevention, Atlanta, United States). Quality control relating to data entry was performed by replicating $10 \%$ of the interviews. Reliability analysis among the data input typists was performed through kappa statistics, which showed a mean value of 1.0 , thus indicating ideal agreement. These analyses were performed using the Statistical Package for the Social Sciences 25.0 software (SPSS 25.0).

\section{Variables}

The dependent variable was full free access within the Brazilian National Health System to the drugs prescribed in the last 30 days. Free access included access to all prescription drugs. The category of free access included medicines received at PCUs and other services of the Municipal Health Department of Belo Horizonte, at specialized component pharmacies and through the Saúde Não Tem Preço (Health Doesn't Have A Price) program at private pharmacies. Specialized component pharmacies are public utilities that provide medicines for specialized care. Under the Saúde Não Tem Preço program, users obtain drugs from private pharmacies without co-payment fees, with costs funded by the Ministry of Health.

The numbers of drugs obtained from public-system pharmacies and private pharmacies were ascertained established. The drugs included in the municipal essential medicines list (MEML) of Belo Horizonte were identified and then classified in accordance with level one of the World Health Organization's Anatomical Therapeutic Chemical (ATC) system. The independent variables were divided as follows: (i) sociodemographic: gender, age, education, skin color, income and marital status (reclassified as with or without a partner); (ii) clinical characteristics: multimorbidity ( $\geq 2$ diseases), ${ }^{15}$ classification of self-reported comorbidities, depressive symptoms and self-perceived health; (iii) functional characteristics: cognition, basic activities of daily living (BADL) and instrumental activities of daily living (IADL); and (iv) pharmacotherapeutic: polypharmacy (use of five or more prescription drugs).

Scales that had been validated or adapted for the Brazilian context were used to evaluate the following variables: depression - 15-item Geriatric Depression Scale (individuals with depressive symptoms: $\geq 6$ points); ${ }^{16}$ cognition - Mini-Mental State Examination (individuals with cognitive disability were defined as those presenting $\leq 13$ points if they were illiterate; $\leq 18$ points if they had had one to eight years of schooling; and $\leq 24$ points if they had had more than eight years of schooling); ${ }^{17,18}$ basic activities of daily living - Katz scale; ${ }^{19}$ and instrumental activities of 
daily living - Lawton and Brody scale (independent individuals $=21$ points $)^{20}$

Self-perceived health was measured by asking the patient: "In general, compared with other people of your age, would you say that your health is excellent, very good, good, fair or poor?" A positive assessment would comprise the responses "excellent", "very good" or "good", whereas a negative assessment would include the other answers, namely, "fair" or "poor".

\section{Statistical analysis}

Descriptive analysis was performed by determining the relative and absolute frequencies of categorical variables, and the median, interquartile range (IQR), minimum ( $\min$ ) and maximum ( $\max$ ) of quantitative variables. The association between free full access to prescription drugs within the Brazilian National Health System and the independent variables was analyzed using Pearson's chisquare test. Continuous variables were dichotomized based on medians or definitions in the literature.

Variables with $\mathrm{P} \leq 0.20$ in univariate analyses were included in a multivariate logistic regression, and those with $\mathrm{P} \leq 0.05$ were retained in the final model. The goodness-of-fit of the final model was evaluated using the Hosmer-Lemeshow test (good fit if $\mathrm{P}>0.05$ ). Data analysis was performed using the SPSS 25.0 software.

\section{Ethical issues}

The research project was approved by the research ethics committees of a public university and of the Municipal Health Department of Belo Horizonte on August 8, 2013, through protocol number CAAE 17339713.40000.5149. The older adults who agreed to participate signed an informed consent statement.

\section{RESULTS}

The characteristics of the 227 elderly people who participated in the study are shown in Table 1 . Their median age was 70 years $(\mathrm{IQR}=12$; minimum $=60$ and maximum $=93)$; most were female $(70.9 \%)$ and the majority had monthly income below two minimum wages $(60.9 \%)$. These older adults predominantly presented preserved cognition (86.1\%), independence in relation to $\mathrm{BADL}(76.5 \%)$ and partial independence in relation to IADL (77.1\%). None of these elderly people were classified as totally dependent in relation to performing BADL or IADL.

Regarding clinical characteristics, the median number of self-reported diseases was three (IQR = 2), and 92.1\% had multimorbidity. The most frequent diseases reported by these elderly people were hypertension (86.3\%), musculoskeletal diseases (34.4\%) and diabetes (32.6\%). A positive self-perception of health was reported by $69.9 \%$ of the participants.

Regarding pharmacotherapeutic characteristics, the median number of medications used by these elderly people was five
Table 1. Description of older adults attended at the two healthcare centers $(n=227)$

\begin{tabular}{cccc}
\multirow{2}{*}{ Variables } & \multicolumn{2}{c}{ Free-access medicines } & $\begin{array}{c}\text { General } \\
\text { description }\end{array}$ \\
\cline { 2 - 4 } & Yes & No & \\
\cline { 2 - 4 } & $\mathrm{n}(\%)$ & $\mathrm{n}(\%)$ & $\mathrm{n}(\%)$
\end{tabular}

\section{Sociodemographic factors}

Gender

Female $\quad 57(35.4) \quad 104(64.6) \quad 161(70.9)$

Male $\quad 34(51.5) \quad 32(48.5) \quad 66(29.1)$

Age

$\leq 70$ years $\quad 53(46.5) \quad 61(53.5) \quad 114(50.2)$

$>70$ years $\quad 38(33.6) \quad 75(66.4) \quad 113(49.8)$

Skin color

Black $20(45.5) \quad 24(54.5) \quad 44(19.5)$

Other

$70(38.5) \quad 112(61.5) \quad 182(80.5)$

Schooling

$\begin{array}{llll}>4 \text { years } & 41(37.3) & 69(62.7) & 110(48.7)\end{array}$

$\leq 4$ years

$49(42.2) \quad 67(57.8) \quad 116(51.3)$

Married

Yes $\quad 42(48.8) \quad 44(51.2) \quad 86(38.4)$

No $\quad 48(34.8) \quad 90(65.2) \quad 138(61.6)$

Income

$>2$ minimum monthly wages $\quad 34(40.5) \quad 50(59.5) \quad 84(39.1)$

$\leq 2$ minimum monthly wages $\quad 51(38.9) \quad 80(61.1) \quad 131(60.9)$

Functional factors

Cognition

Preserved $\quad 79(41.1) \quad 113(58.9) \quad 192(86.1)$

Suspected disability $\quad 12(38.7) \quad 19(61.3) \quad 31(13.9)$

Instrumental activities of daily living

$25(48.1) \quad 27(51.9) \quad 52(22.9)$

Partially dependent $\quad 66(40.1) \quad 136(59.9) \quad 175(77.1)$

Basic activities of daily living

Independent

Dependent $\geq$ one activity

$73(42.2) \quad 100(57.8) \quad 173(76.5)$

Clinical factors

Multimorbidity

$\begin{array}{llll}\text { Yes } & 78(37.3) & 131(62.7) & 209(92.1)\end{array}$

No $13(72.2) \quad 5(27.8) \quad 18(7.9)$

Arterial hypertension

$\begin{array}{llll}\text { Yes } & 79(40.3) & 117(59.7) & 196(86.3)\end{array}$

No $\quad 12(38.7) \quad 19(61.3) \quad 31(13.7)$

Diabetes mellitus

Yes $24(32.4) \quad 50(67.6) \quad 74(32.6)$

No $\quad 67(43.8) \quad 86(56.2) \quad 153(67.4)$

Asthma and chronic obstructive

pulmonary disease

$\begin{array}{llll}\text { Yes } & 10(29.4) & 24(70.6) & 34(15.0)\end{array}$

No $\quad 81(42.0) \quad 112(58) \quad 193(85.0)$

Depressive symptoms

$\begin{array}{llll}\text { Yes } & 17(34.0) & 33(66.0) & 50(22.5)\end{array}$

$\begin{array}{llll}\text { No } & 74(43.0) & 98(57.0) & 172(77.5)\end{array}$

Self-perceived health

Positive $63(39.9) \quad 95(60.1) \quad 158(69.9)$

Negative

$28(41.2) \quad 40(58.8) \quad 68(30.1)$

Pharmacotherapeutic factors

Polypharmacy

Yes $\quad 44(33.1) \quad 89(66.9) \quad 133(58.6)$

No $\quad 47(50.0) \quad 47(50.0) \quad 94(41.4)$ 
$(\mathrm{IQR}=3 ;$ minimum $=1$ and maximum $=13)$, and $58.6 \%$ were using polypharmacy.

Figure 1 shows the characterization of access to medicines among these 227 older adults. Among them, 67 (29.5\%) reported having full access to all medicines at the PCU pharmacies investigated. Access to at least one drug in the PCU pharmacies surveyed was reported by $32(14.1 \%)$ of these older adults. We found that $128(56.4 \%)$ of these elderly people had bought or received at least one drug through a channel other than the PCU.

The analysis on medicines that were not accessed at PCU pharmacies showed that the access strategies most used by the elderly people were the following: acquisition at a private pharmacy with the total amount paid by the user (41.9\%); free access through the Saúde Não Tem Preço program (25.0\%); and access through the popular pharmacy program, with acquisition subsidized by the Ministry of Health with co-payment fees (23.4\%), as shown in Figure 1. Full access to the prescribed drugs was observed.

In total, 91 (40.1\%) of these older adults had free full access to prescription drugs within the Brazilian National Health System. The median proportion of prescribed medications that were provided through the Brazilian National Health System was $83 \%$ $(\mathrm{IQR}=33$; minimum $=17$ and maximum $=100)$. The median number of medicines accessed through the Brazilian National
Health System was $4(\mathrm{IQR}=3)$, and the median number of medicines accessed through private pharmacies was $1(\mathrm{IQR}=1$; minimum $=1$ and maximum $=7)$. All the drugs used by $179(78.9 \%)$ of these older adults were included in MEML.

The drugs used by the elderly people were predominantly from the following anatomical groups (level 1) of the ATC classification: group C - circulatory system (50.5\%); group A - alimentary tract and metabolism (17.4\%); and group $\mathrm{N}$ - nervous system $(12.9 \%)$. On the other hand, analysis on drugs that were not included in RENAME and which were accessed through private pharmacies showed that the most frequent ATC groups were the following: group C (41.4\%); group N (20.0\%); and group B - blood and hematopoietic organs (12.9\%) (Table 2). Univariate analysis on the associations between full access to medicines within the Brazilian National Health System and the independent variables (Table 3) showed that associations with the following factors were present at a 5\% significance level: female, age $\leq 70$ years, married, polypharmacy, multimorbidity and cardiovascular disease.

In the final logistic regression model, the presence of polypharmacy (odds ratio, $\mathrm{OR}=0.47$; confidence interval, $\mathrm{CI}=0.268$ $0.838)$ and multimorbidity $(\mathrm{OR}=0.26 ; \mathrm{CI}=0.087-0.775)$ was negatively associated with full access to medicines within the Brazilian

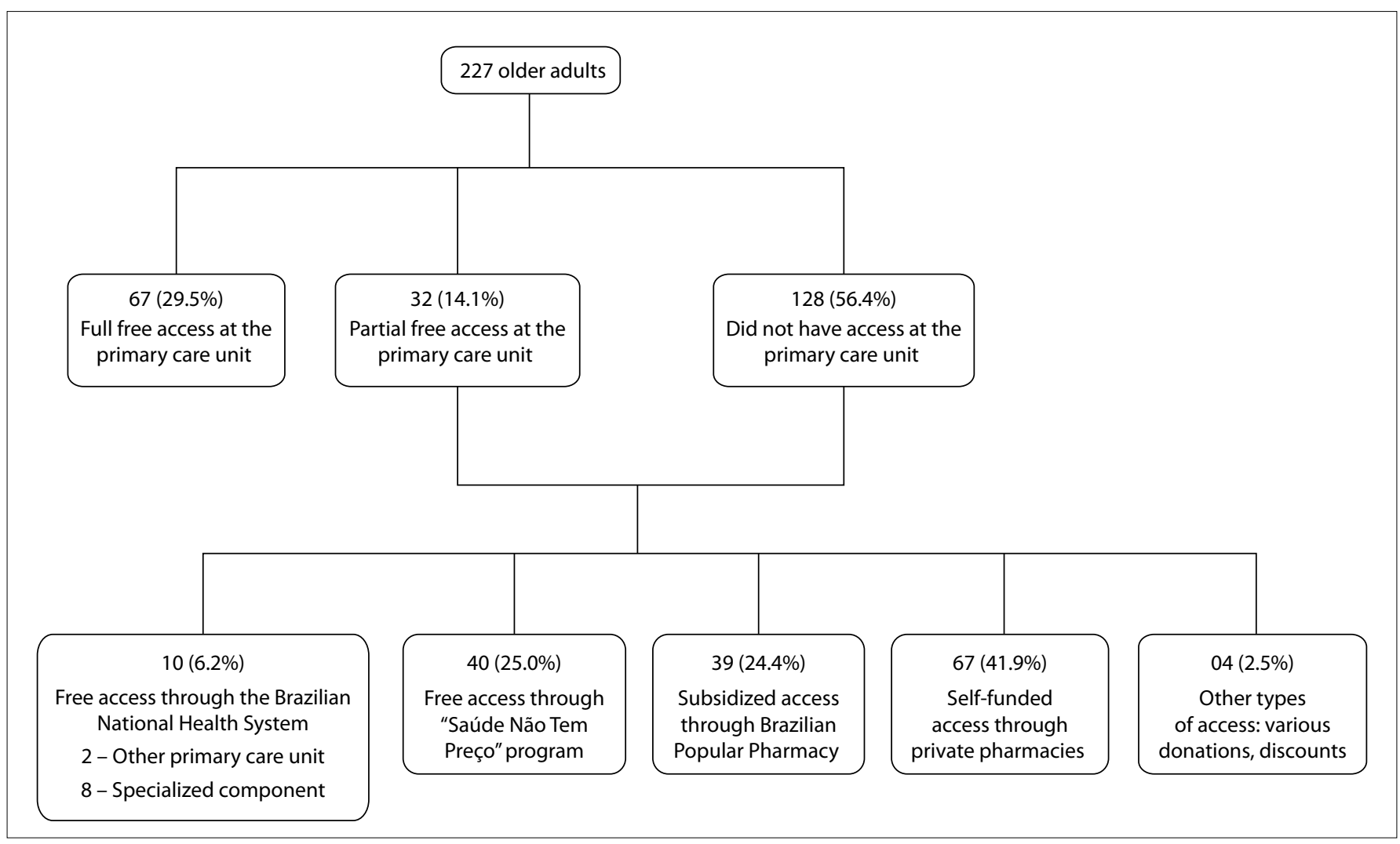

Figure 1. Characterization of access to medicines among the 227 older adults. 
Table 2. Medicines acquired outside of the municipal essential medicines list (MEML)

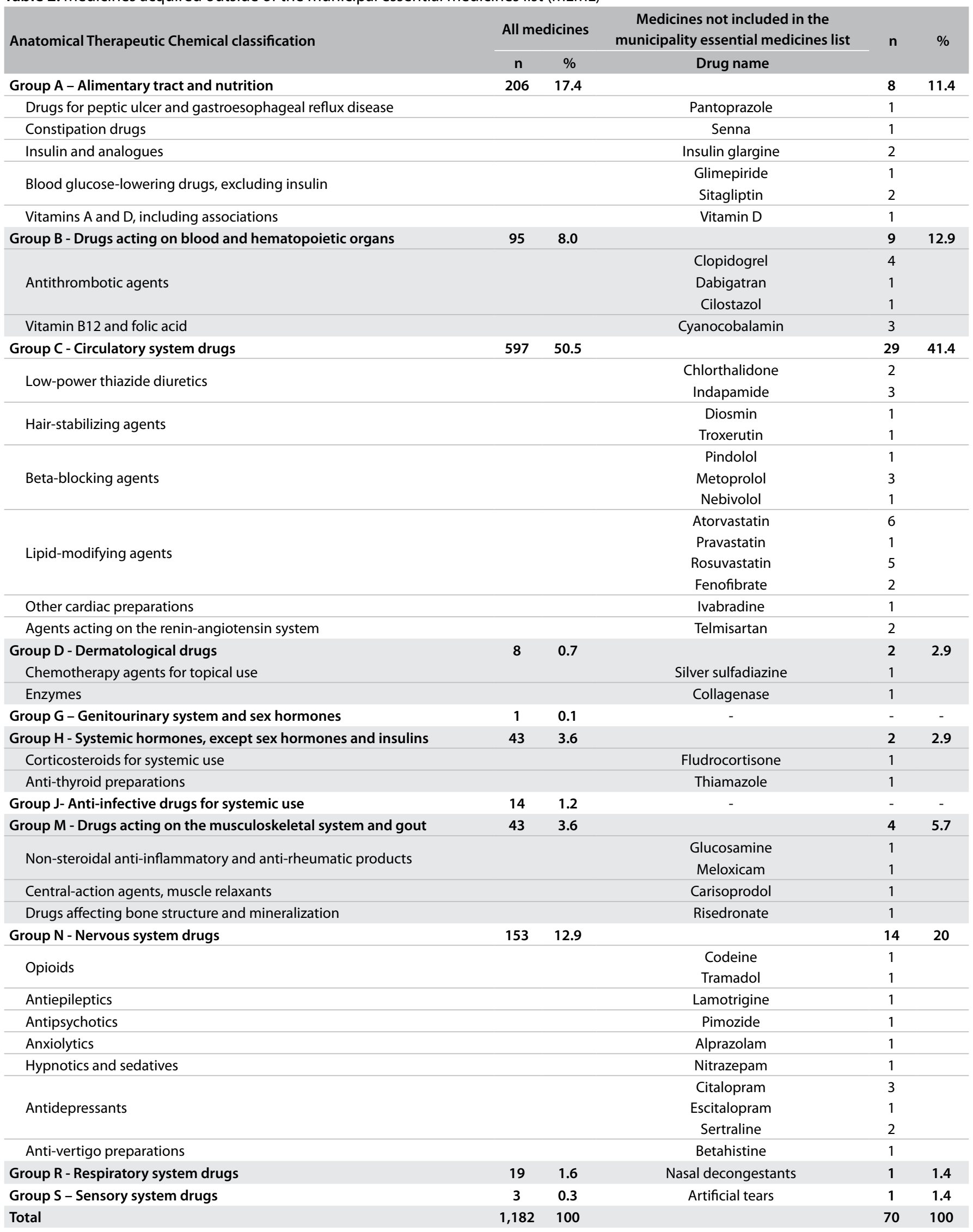


National Health System. Age $\leq 70$ years $(\mathrm{OR}=1.92$; CI $=1.092$ 3.380) was positively associated with full access to medicines in the Brazilian Unified Health System (Table 3).

\section{DISCUSSION}

This study showed that $40 \%$ of the older adults surveyed had free full access to prescription drugs within the Brazilian National

Table 3. Univariate and multivariate analysis on the factors associated with free full access to medicines within the Brazilian National Health System

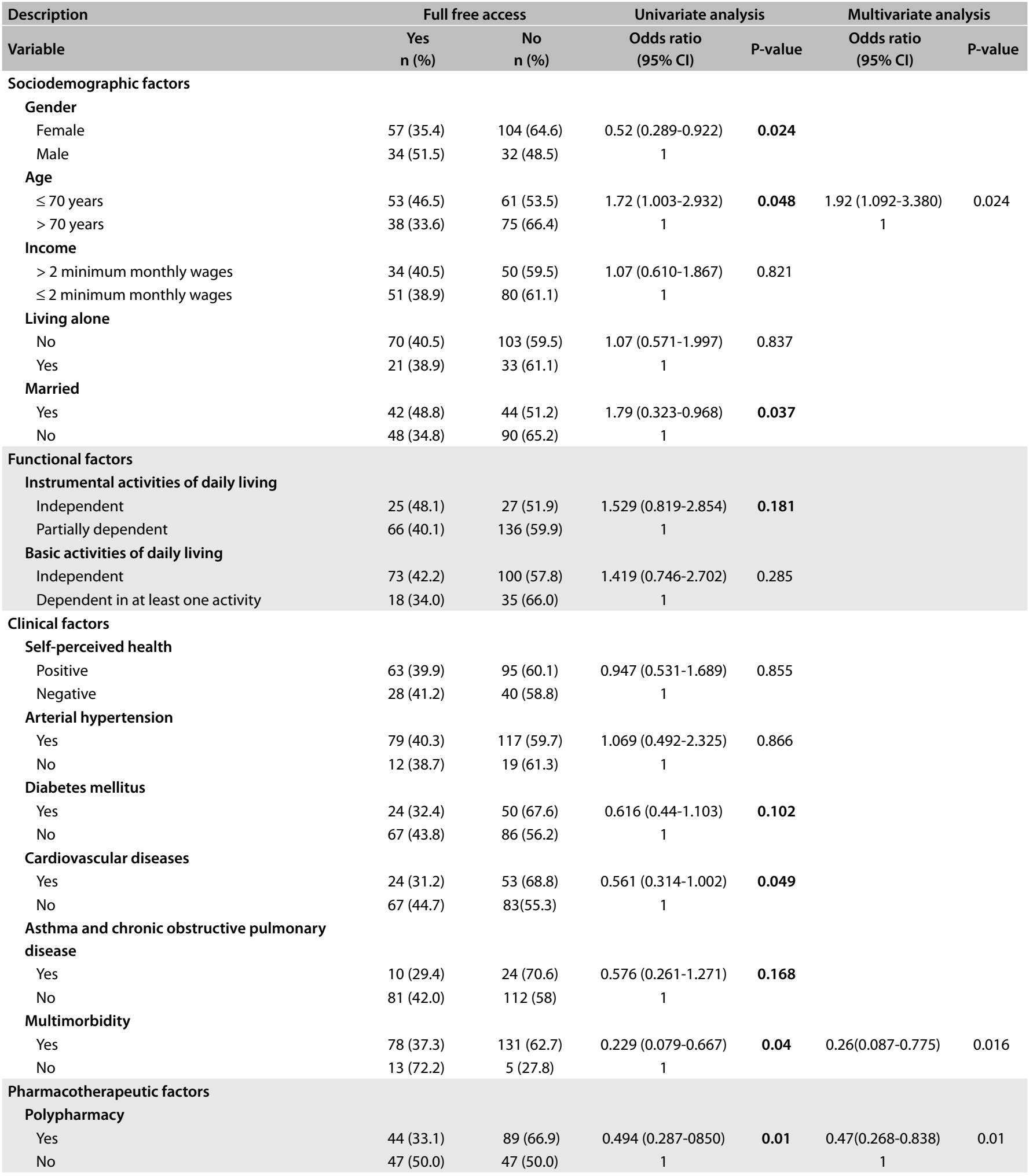

Hosmer and Lemeshow test: chi-square $=4.780$; degrees of freedom $=4 ; \mathrm{P}=0.311$. 
Health System. Given the greater burden of noncommunicable diseases among elderly people, ensuring access to drugs for this age group in order to provide more effective control of these diseases, thereby contributing towards improving the capacity of actions provided to this population to resolve problems, is a priority. Among the guidelines and constitutional principles of the Brazilian State is that it guarantees comprehensive therapeutic care. Therefore, access to medicines is a citizen's right. ${ }^{4}$

The proportion of individuals with free full access to medicines within the Brazilian National Health System has ranged from $45.1 \%$ to $50.0 \%$ in investigations based on data obtained from the National Survey on Drug Access, Use and Promotion of Rational Use $e^{4}$ and the National Household Sample Survey (NHSS). ${ }^{9,11}$ The prevalence findings from the present study are in line those from other Brazilian studies, but comparisons should be made with caution because of methodological variations and inclusion criteria, given that the drug access survey and the study by Boing ${ }^{11}$ using NHSS data did not include older adults alone.

Despite the strategies implemented to conform with the guidelines of the National Drug Policy and the National Pharmaceutical Services Policy, investigations have shown that only about half of citizens with prescription drugs fully obtain them from the Brazilian National Health System. ${ }^{4}$ An economic evaluation from the perspective of the public healthcare system showed that medicines supplied through the primary public healthcare services of municipalities in the state of Minas Gerais had lower cost than those supplied through the Aqui tem Farmácia Popular do Brasil (The Brazilian popular pharmacy program is here) program, in which the Ministry of Health subsidizes the drug cost and the user pays co-payment fees for certain drugs purchased from private pharmacies. ${ }^{21}$ New evaluations on the effectiveness of expanding drug access policies such as free treatment for hypertension, diabetes and asthma through the popular pharmacy program may provide elements for increasing free access to medicines within the Brazilian National Health System.

Full access to medicines through healthcare centers was reported by around one-third of the older adults surveyed here. This shows that the availability of access needs to be streamlined to ensure drug provision and improve geographical accessibility. Thus, it is crucial to improve the management of pharmaceutical care to increase the effectiveness of free access to drugs for the population, and to improve the availability of medicines in public healthcare facilities. ${ }^{4,7}$ Improved management will contribute towards easing the challenge that the Brazilian National Health System faces in ensuring universal and continuous access to medicines, with equity and a capacity to resolve problems for the population

Most of the medicines used by the elderly people studied here were included in the municipal essential medicines list (MEML). This is a positive aspect of the way in which pharmaceutical services have been organized. It contributes towards implementation of access expansion actions, given that this facilitates the scheduling and dispensing steps. It also contributes towards rational use of drugs, since medicines included in the MEML are generally safe and effective.

A study conducted in primary healthcare centers in Belo Horizonte found a positive association between presence of the drug in the MEML and user access to it in the PCU. ${ }^{22}$ On the other hand, an analysis on drugs used by older adults that were not included in the MEML showed that from the perspective of elderly people's care, therapeutic gaps existed. Absences of drugs such as cyanocobalamin, citalopram, clopidogrel, sertraline and escitalopram, which do not have substitutes in the drug list of the municipality investigated, were identified. In providing care for older adults, it is essential to develop actions to promote rational use of medicines and to implement strategies to ensure access to safe medications that are appropriate for the specificities of drug therapy in this population group. It is essential to consider the specificities of the older adult population ${ }^{23}$ in selecting drugs and also in relation to other stages of pharmaceutical services.

The feminization of aging, ${ }^{24}$ as well as the greater use of medicines by women, explain the lower likelihood of free access to medicines that was found in our study. On the other hand, the higher likelihood of free access among married older adults that was also observed illustrates the notion that family support can contribute towards healthcare. This increases the likelihood of access through more significant support for seeking drug provision strategies.

Cardiovascular diseases contribute significantly towards the burden of disease among older adults. ${ }^{4,25}$ They require the use of multiple medications, which thus reduces the likelihood of free full access. Some elderly people with cardiovascular diseases may require drugs that are not included in the MEML, in order to streamline therapeutic endpoints, and this also reduces the likelihood of access. Circulatory system drugs, along with those that act on blood and hematopoietic organs, are among the drugs excluded from the MEML, yet these drugs are widely used by older adults.

Free access to medications independently showed a direct association with age $\leq 70$ years and indirect associations with polypharmacy and multimorbidity. The associations observed in relation to these factors can be explained by the fact that elderly people with higher numbers of chronic diseases demand more meaningful use of medicines, which reduces the likelihood of access to prescribed drugs. ${ }^{13}$ Understanding the specificities of drug therapy among older adults, the determinants of their drug use and the factors associated with access is vital for enabling development of actions towards greater availability of drugs and for improving the quality of pharmaceutical services for this population group within the Brazilian National Health System.

One strength of this study was that it analyzed the factors associated with free access to medicines through considering the 
pharmacotherapeutic, clinical and sociodemographic aspects of access. Thus, it provided elements to support evaluation of the way in which pharmaceutical services are organized within the Brazilian National Health System. This study therefore helps towards reducing the challenge of ensuring universal, equitable and problem-resolving access.

This study has some limitations. Firstly, it was conducted only in two PCUs in a single Brazilian city, which thus does not allow generalizations. Secondly, only older adults who attended the PCU to receive medications were selected for the study. This may have led to selection bias, with greater inclusion of individuals with lower degrees of frailty. Thirdly, the evaluation of access to medicines covered only the prescriptions held at the time of the interview. It may have been the case that, at that time, these older adults did not have all the prescriptions for the medicines that they were using, which would have induced bias regarding the number of medicines. Another limitation relates to the information about comorbidities, which was self-reported, thus reducing the quality of this clinical information.

Investigations on access to medicines are important because they provide elements for characterizing the healthcare system and for supporting policies and actions aimed at increasing access to priority groups such as older adults. ${ }^{9}$

\section{CONCLUSION}

Free access to medicines is determined by the demographic, clinical, and pharmacotherapeutic characteristics of elderly people. Age $\leq 70$ years increases the likelihood of free access, and older adults with multimorbidity and polypharmacy use have a lower likelihood of free full access to medicines. Access to medicines within the Brazilian National Health System among the elderly people surveyed here was high, but less than half of them were covered by full free access to prescription drugs. The availability of drugs in the PCUs was insufficient, which thus compromised the provision of drugs to older adults and geographical accessibility. Identification of factors associated with free access to medication among the elderly provides elements for guiding the Brazilian National Health System in implementing actions to improve access, such as the restructuring of pharmaceutical services to meet the specificities of the older adult population.

\section{REFERENCES}

1. Godman B, Malmström RE, Diogene E, et al. Are new models needed to optimize the utilization of new medicines to sustain healthcare systems? Expert Rev Clin Pharmacol. 2015;8(1):77-94. PMID: 25487078; doi: 10.1586/17512433.2015.990380.

2. Ramos LR, Tavares NU, Bertoldi AD, et al. Polypharmacy and Polymorbidity in Older Adults in Brazil: a public health challenge. Rev Saude Publica. 2016;50(suppl 2):9s. PMID: 27982377; doi: 10.1590/ S1518-8787.2016050006145.
3. Oliveira MA, Luiza VL, Tavares NU, et al. Access to medicines for chronic diseases in Brazil: a multidimensional approach. Rev Saude Publica. 2016;50(suppl2):6s. PMID: 27982382; doi: 10.1590/S15188787.2016050006161.

4. Tavares NU, Luiza VL, Oliveira MA, et al. Free access to medicines for the treatment of chronic diseases in Brazil. Rev Saude Publica. 2016;50(suppl 2):7s. PMID: 27982374; doi: 10.1590/S1518-8787.2016050006118.

5. WirtzVJ, Moucheraud C. Beyond availability and affordability: how access to medicines affects non-communicable disease outcomes. Lancet Public Health. 2017;2(9):e390-e391. PMID: 29253405; doi: 10.1016/ S2468-2667(17)30168-8.

6. World Health Organization (WHO). Global Action Plan for the Prevention and Control of NCDs 2013-2020; 2013. Available from: https://www. who.int/nmh/events/ncd_action_plan/en/. Accessed in 2020 (Feb 3).

7. Álvares J, Guerra AA Junior, Araújo VE, et al. Access to medicines by patients of the primary health care in the Brazilian Unified Health System. Rev Saude Publica. 2017;51 (suppl 2):20s. PMID: 29160463; doi: 10.11606/S1518-8787.2017051007139

8. Aziz MM, Calvo MC, Schneider IJ, Xavier AJ, d'Orsi E. Prevalência e fatores associados ao acesso a medicamentos pela população idosa em uma capital do sul do Brasil: um estudo de base populacional [Prevalence and factors associated with access to medication among the elderly in a city in southern Brazil: a population-based study]. Cad Saúde Pública. 2011;27(10):1939-50. PMID: 22031198; doi: 10.1590/s0102$311 \times 2011001000007$.

9. Viana KP, Brito Ados S, Rodrigues CS, Luiz RR. Access to continued-use medication among older adults, Brazil. Rev Saude Publica. 2015;49:14. PMID: 25741646; doi: 10.1590/s0034-8910.2015049005352.

10. Bertoldi AD, de Barros AJ, Wagner A, Ross-Degnan D, Hallal PC. Medicine access and utilization in a population covered by primary health care in Brazil. Health Policy. 2009;89(3):295-302. PMID: 18722031; doi: 10.1016/j.healthpol.2008.07.001.

11. Boing AC, Bertoldi AD, Boing AF, Bastos JL, Peres KG. Acesso a medicamentos no setor público: análise de usuários do Sistema Único de Saúde no Brasil [Access to medicines in the public sector: analysis of users of the Brazilian Unified National Health System]. Cad Saúde Pública. 2013;29(4):691-701. PMID: 23568299; doi: 10.1590/S0102$311 \times 2013000400007$

12. Drummond ED, Simões TC, Andrade FB. Access to prescribed medicine in the Brazilian adult population. Rev Bras Epidemiol. 2018;21:e180007. PMID: 30088587; doi: 10.1590/1980-549720180007.

13. Paniz VM, Fassa AG, Facchini LA, et al. Acesso a medicamentos de uso contínuo em adultos e idosos nas regiões Sul e Nordeste do Brasil [Access to continuous-use medication among adults and the elderly in South and Northeast Brazil]. Cad Saúde Pública. 2008;24(2):267-80. PMID: 18278273; doi: 10.1590/s0102-311×2008000200005.

14. Dean AG, Sullivan KM, Soe MM. OpenEpi: Open Source Epidemiologic Statistics for Public Health, Version 3.01. 2017. Available from: www. openepi.com. Accessed in 2020 (Feb 3). 
15. Harrison C, Britt H, Miller G, Henderson J. Examining different measures of multimorbidity, using a large prospective cross-sectional study in Australian general practice. BMJ Open. 2014;4(7):e004694. PMID: 25015470; doi: 10.1136/bmjopen-2013-004694.

16. Paradela EM, Lourenço RA, Veras RP. Validação da escala de depressão geriátrica em um ambulatório geral [Validation of geriatric depression scale in a general outpatient clinic]. Rev Saúde Pública. 2005;39(6):91823. PMID: 16341401; doi: 10.1590/s0034-89102005000600008.

17. Bertolucci PHF, Brucki SMD, Campacci SR, Juliano Y. O mini-exame do estado mental em uma população geral: impacto da escolaridade [The Mini-Mental State Examination in an outpatient population: influence of literacy]. Arq Neuropsiquiatr. 1994;52(1):1-7. doi: 10.1590/ S0004-282X1994000100001.

18. Lourenço RA, Veras RP. Mini-Exame do Estado Mental: características psicométricas em idosos ambulatoriais [Mini-Mental State Examination: psychometric characteristics in elderly outpatients]. Rev Saúde Pública. 2006;40(4):712-9. PMID: 16906312; doi: 10.1590/s003489102006000500023.

19. LinoVT, Pereira SR, Camacho LA, Ribeiro Filho ST, Buksman S. Adaptação transcultural da Escala de Independência em Atividades da Vida Diária (Escala de Katz) [Cross-cultural adaptation of the Independence in Activities of Daily Living Index (Katz Index)]. Cad Saúde Pública. 2008;24(1):103-12. PMID: 18209838; doi: 10.1590/s0102-311×2008000100010.

20. Santos RL, Virtuoso Jr JS. Confiabilidade da Versão Brasileira da Escala de Atividades Instrumentais da Vida Diária [Reliability of the Brazilian version of the Scale of Instrumental Activities of Daily Living]. RBPS. 2008;21(4):290-6. Available from: https://periodicos.unifor.br/RBPS/ article/viewFile/575/2239. Accessed in 2020 (Jan 9).

21. Garcia MM, Guerra AA Júnior, Acúrcio FA. Economic evaluation of the Programs Rede Farmácia de Minas do SUS versus Farmácia Popular do Brasil. Cien Saude Colet. 2017;22(1):221-33. PMID: 28076545; doi: 10.1590/1413-81232017221.15912015.

22. Dutra KR, Martins UCM, Lima MG. Availability and accessibility to medicines in Primary Health Care in a Brazilian Region. J Young Pharm. 2016;8(3):2558. Available from: https://pdfs.semanticscholar.org/03ec/6ff82ca35299f 974337a122f6f96cd41a435.pdf. Accessed in 2020 (Jan 9).

23. Lopes LM, Figueiredo TP, Costa SC, Reis AM. Use of potentially inappropriate medications by the elderly at home. Cien Saude Colet. 2016;21(11):3429-38. doi: 10.1590/1413-812320152111.14302015.

24. Lima LCV, Bueno CMLB. Envelhecimento e gênero: a vulnerabilidade de idosas no Brasil. Revista Saúde e Pesquisa. 2009;2(2):273-80. Available from: https://periodicos.unicesumar.edu.br/index.php/saudpesq/ article/view/1173/792. Accessed in 2020 (Feb 3).

25. Prince MJ, Wu F, Guo Y, et al. The burden of disease in older people and implications for health policy and practice. Lancet. 2015;385(9967):54962. PMID: 25468153; doi: 10.1016/S0140-6736(14)61347-7.
Authors' contributions: Pinto IVL, Reis AMM, Ceccato MGB, Lima MG, Silveira MR and Pantuzza LLN conceived and designed the study. Pinto IVL, Reis AMM and Ceccato MGB acquired and interpreted the data, performed the statistical analysis, analyzed and interpreted the data and critically reviewed the manuscript. Pinto IVL, Reis AMM and Lima MG drafted the manuscript. Pantuzza LLN and Silveira MR interpreted the data and critically reviewed the manuscript. The final manuscript was approved by all authors

Acknowledgements: Fundação de Amparo à Pesquisa do Estado de Minas Gerais (FAPEMIG) and Pró-Reitoria de Pesquisa da Universidade Federal de Minas Gerais (UFMG)

Sources of funding: This study was financed by Fundação de Amparo à Pesquisa do Estado de Minas Gerais (FAPEMIG) (grant number APQ03519-13) and by the Pró-Reitoria de Pesquisa da Universidade Federal de Minas Gerais (UFMG)

Conflict of interests: The authors declare that there was no conflict of interest

Date of first submission: December 20, 2019

Last received: February 10, 2020

Accepted: February 19, 2020

\section{Address for correspondence:}

Adriano Max Moreira Reis

Universidade Federal de Minas Gerais (UFMG)

Av. Antônio Carlos, 6.627

Pampulha — Belo Horizonte (MG) — Brasil

CEP 31270-901

Tel. (+55 31) 3409-6943

E-mail:amreis@outlook.com 